\title{
The Causality Between Energy Consumption and Economic Growth in Nigeria (1981 - 2009).
}

\author{
${ }^{1}$ Atoyebi Kehinde .O, ${ }^{2}$ Adekunjo Felix .O, ${ }^{3}$ Kadiri Kayode .I, \\ ${ }^{4}$ Ogundeji Musibau .O. \\ ${ }^{1,2,3,4}$ Lagos State University, Ojo Dept. Of Economics.
}

\begin{abstract}
This study seeks to determine the direction of causality between energy consumption (EC) and economic growth (EG), using annual data from 1981 to 2009. In our empirical analysis, we run an ordinary least square test to verify the statistical significance of the variables used and augmented form of Granger causality test to identify the direction of the relationship between these variables in the short run. Empirical investigations reveal that two variables are statistically significant at 5\% and these variables are gross fixed capital formation and total labour force and they are positively related to real GDP while other variables such as crude oil consumption, coal consumption are positively related to real GDP but not statistically significant. Total electricity consumption on its own exert a negative influence on real GDP and also not statistically significant.

Our findings based on Granger causality test suggest the existence of a unidirectional causal relationship between real GDP and crude oil consumption with direction from crude oil consumption. Also, we found out the existence of a uni-directional causal relationship between real GDP and gross fixed capital formation and total labour force with direction from the gross domestic product to the two variables. Meanwhile, causality relationship is virtually inexistence between coal consumption, total electricity consumption and real GDP.

Based on our findings, the study therefore recommends that Nigeria government should invest more in energy sector, particularly in crude oil and natural gas and this is because our results shows that crude consumption Granger cause economic growth.
\end{abstract}

Key words: Energy consumption, Economic growth, electricity consumption, Nigeria.

\section{Introduction}

Energy plays a central role in the economic development of any nation. It enhances the productivity of factors of production and increases the standard of living of the citizen. It has been widely acknowledged that economic growth and energy consumption are interconnected. The interconnection between economic growth and energy consumption has been well established in the literature, yet the direction of causation of this interconnectivity still remains controversial. That is whether economic growth induces energy consumption or that energy consumption cause economic growth. The controversial issues stems on the ground that if the marginal social benefit of economic growth exceed the marginal cost of energy, use then it is worthwhile to increase energy consumption otherwise, if energy use cannot improve economic growth, a reduction in energy intensity could be justified to avoid the negative impact on the economy.

Moreover, some energy economists have argued that energy is a crucial input along with other factors of production such as capital and labour. Therefore, energy is a fundamental factor for economic growth and is potentially an inhindrance to economic and social development. However, some argued that the cost of energy consumption is a small portion of gross domestic product, therefore having a significant impact on economic growth is unfounded.

However, the causality between economic growth and energy consumption is needed to be determined because it will assist the governments to formulate an appropriate policy on energy conservation.

Basically, if energy consumption causes economic growth then reducing energy consumption could stimulate unemployment, budget deficit, low income etc. But, if it is established that energy consumption does not Granger causes GDP, then energy conservation may be adopted with no negative impact on the economy.

In the light of this background, this study attempts to determine the causal relationship between energy consumption and GDP in Nigeria from the period of 1970 through 2010.

Also, to discuss the main sources of energy in Nigeria and how they contribute to economic growth.

The objectives highlighted will be accomplished by examining Granger causality between growth in energy consumption and GDP growth and between growth in energy consumption and employment growth by employing cointegration technique and Hsiao's version of Granger causality. To further enrich our study we have also analysed the sectoral relationship viz, petroleum, gas and electricity consumption with that of GDP growth. 
Since energy consumed consists of both domestic and imported sources, it could be useful to outline appropriate policies regarding each component.

The paper is organised as follows:

Section I discusses the selected existing literature. Empirical findings are presented in section III. The final section contains concluding remarks.

\section{Selected Existing Literature}

Detailed and historical studies have provided empirical validation of the views that energy consumption Granger causes economic growth.

The studies by Pachaurri (1977) and Tyner (1978) found that there was a strong correlation between economic growth and energy consumption in India.

$\mathrm{Yu}$ and Choi (1985) estimated the causal relationship between energy consumption and economic growth (GNP) of five countries, concluded that there was unidirectional causality from GNP to Philippines and Energy consumption in South reverse comicality from GNP to be Korea, but no causality in the USA, UK and Poland.

Riaz (1984) investigated the relationship between energy consumption and economic growth using log linear regression analysis. The regression analysis of the energy-growth relationship has shown independence between socio economic variables and energy consumption.

Masih and Masih (1996) found a cointegrated relationship between energy consumption and GDP in India, Pakistan, and Indonesia, but no such evidence in the ca... of Malaysia, Singapure and Philippines. Yang (2000) investigated the causal relationship between GDP and energy consumption which includes coal, natural gas and electricity analyzing the aggregate as well as several disaggregated categories and found a bidirectional causality between total energy consumption and GDP in India; while that of Pakistan and Indonesia, GDP was found to cause energy consumption.

Erol and $\mathrm{Yu}$ (1987), tested data for six industrialized countries, and found no significant causal relationship between energy consumption and GDP growth between energy consumption and GDP growth and, energy and employment. Yu, et al. (1988). Found no relationship between energy and GDP, between energy and employment in the cace of United States. Using Granger method, they detected that energy consumption negatively effected employment by employing sim's techniques. A bidirectional causality between growth of energy consumption and GDP growth was observed in Taiwan Province of China by Hwing. et. Al. (1991), while Cheg and Lai, (1997), found causality from economic growth to energy consumption and from energy consumption employment without feedback in Taiwan Province of China.

Sari (2006) argued that the lack of consensus on the causality between energy and out put might be due to the fact that different economies have different energy consumption patterns and various sources might have varying impacts on the economy.

A pioneer study conducted by Kraft and Kraft (1978) examined the relationship between USA energy consumption and GDP for the period 1947 and 1974. The study found a unidirectional causality from GNP to energy consumption.

Akarea and Lung (1980) using the same USA for 1947-1972 examined the same relationship and found no relationship between the variables.

Also Erol and Yu (1987) using bivariate models tested the relationship between energy consumption and GDP for six selected developed economies, namely; Canada, England, France, Germany, Italy and Japan with data for 1952-1982 period.

The study found a bidirectional causal relationship for Japan a unidirectional from energy consumption to GDP for Canada and unidirectional from GDP to energy consumption for Germany and Italy. They found no causality for France and England Stern (2000) also examine the causal relationship between energy consumption and GDP in USA for 1948-1994 periods, using multivariate model. The study found no relationship between the variable. Masiti \& Masih (1996) using a cointegration analysis and vector auto regressive model examined the causal relationship among energy consumption, employment- energy consumption, but only unidirectional causality running from energy consumption to output Soytas and Sari (2003) tested the causality between energy consumption and GDP in the (10) ten emerging markets excluding China and G-7 countries. They found out bidirectional causality in Argentina, unidirectional causality ruining from energy consumption to GDP in Turkey, France, Germany, Japan and from GDP to energy consumption in Korea and Italy. Soytas, Sari and Ozdemir (2001) examined the relationship between energy consumption and GDP for Turkey for the period between 1960 and 1995 and found a unidirectional relationship from energy consumption to GDP for the period. Chontanawat, Hunt and Pierse (2006) tested the causality between energy and GDP for 30 OECD and 78 non-OECD countries. Their findings show that causality from aggregate energy consumption to GDP and GDP to energy consumption is more prevalent in the advance OECD countries compared to the developing non-OECD countries. Those findings imply that a policy to reduce energy 
consumption aimed at reducing emission is likely to have greater impact on the GDP of the developed rather than the developing world.

Apart from those studies which examined energy, as a whole, some studies examine energy by separating it into us its subcomponent such as electricity and petroleum. Ghosh (2002) examined economic growth and electricity in India between 1950 and 1997. He found a unidirectional causality from economic growth to electricity consumption. Also Jumbe (2004) examined the relationship between electricity consumption and GDP for Malawi for the period between 1970 and 1999 and found a bidirectional causal relationship. He also examined the relationship between non-agricultural and electricity consumption and found a unidirectional relationship causality relationship from GDP to energy consumption. Erbaykal (2008) investigated the relationship between economic growth and energy disaggregates using oil and energy 19702003 period in Turkey using bounds test approach to cointegration, the study found that in the short run; both oil and electricity consumption have positive significant effect on economic growth. In the long run, however, oil consumption has positive but insignificant on economic growth while electricity consumption has a negative and insignificant effect on the economic growth. The study infers that both electricity and oil consumption have short run effect on economic growth.

A similar study would be beneficial in the case of Nigeria to design an economic policy frame work for the energy and other sectors.

\subsection{SECTORAL ANALYSIS OF ENERGY SECTOR COAL ENERGY:}

The historical evidence have it that coal was the first energy resources to be exploited in Nigeria with its proven reserve capacity of 2 billion tonnes. The relevance of coal began to drop as soon as the oil was discovered. As of today, it is insignificantly need as an energy resource. Nigeria coal are mainly located in Anambra State and it is sub bituminous with low sulphur content.

The nature of the coal has attracted some countries in Africa and in Europe; it is argued that coal production potential per year is between 400,000 to 800,000 tonnes per year respectively (World Bank, 1984). This potential remained untapped till today.

\section{NATURAL GAS:}

Nigeria is endorsed with a huge gas reserve, infact, the petroleum experts regard Nigeria "as a gas province with little oil in it" (Gailes Obaseki, 1996). Nigeria gas reserve is estimated to be about 124 trillion cubic feet (TCF) of gas in 2005 which in terms of energy it is said to be twice as much as the nation's crude oil reserve.

The Natural gas in Nigeria is obtainable in two forms - Associated natural gas (AG) and as Non associated natural gas (Non - AG). Approximately 75 percent of the total gas output are flared in 2000. This could be broken down into 8 percent of non associated gas and 92 percent of the associated gas output (NNPC, 2008).

This wastage was because of lack of infrastructure that could have boosted supply and increase revenue.

\section{ELECTRICITY:}

Undoubtedly, Nigeria power sector is marked by low generating capacity relative to installed capacity and $40 \%$ of the citizens have access to uninterrupted supplies of electricity. Presently, electricity generation ranges from between 2,500 megawatts to about 3,000. The potential demand in the next few years is estimated at about 1,500 mega watts. As at 2005, the installed electricity generation capacity was approximately 6,861 megawatts (MW). The wide gap between the installed capacity and total electricity generation capacity started emerging in 1978. Thus, making power outages to be frequent and the sector operates below its estimated capacity. Though, low water levels at Kanji, Jebba and Shiroro hydropower status are frequently claimed to be responsible for this power shortages, while in Lagos, Egbin, Delta and Porthacourt Afam plants are also operating at below capacity due to poor maintenance. At present, Nigeria government has been making effort to increase foreign participation in the power sector by commissioning Independent Power Producers (IPPS) to generate electricity and sell it to PHCN, sourcing for investors for the construction of new Independent Power Plants (IPPS). IPPS is currently under construction with $276 \mathrm{MW}$ siemen station in Afam, Agips, 450 - MW plant in Kwale, Exon Mobil's, 388 - MW plant in Bonny, ABB'S 450 - MW plant in Abuja and Eskom's 388 MW plant in Enugu. The government has also approved the construction of four thermal power plants with a combined capacity of 1, $234 \mathrm{MW}$ to meet its generating goal of 6,500 MW by 2006: Geregu, Alaoji, Papalanto and Omotosho.

Fourteen hydroelectric and natural gas plants are planned for completion by 2010 .

Summarily, with the effort of the government towards this sector, there are optimistic view that power generation and transmission in Nigeria will likely improve in the next few years to come. 


\section{Model Specification And Empirical Results}

Ordinary Least Square (OLS) method of analysis is employed to examine the relationship between real GDP and other variables in our study

\section{MODEL SPECIFICATION}

In order to determine the impact of these variables on the real GDP, the multiple regression equation is explicitly specified in functional form as follows:

$\mathrm{RGDP}=\mathrm{f}(\mathrm{CLC}, \mathrm{COC}, \mathrm{ETC}, \mathrm{GFCF}, \mathrm{TLF})$

Where RGDP $=$ Real Gross domestic product is dependent variable

\section{Definition of terms}

CLC $=$ Coal Consumption

$\mathrm{COC}=$ Crude Oil Consumption

$\mathrm{TEC}=$ Total Electricity Consumption

GFCF $=$ Gross Fixed Capital Formation

TLF $=$ Total Labour Force

Equation 1 can be specifically expressed in explicit econometric form as follows:

$R G D P=\alpha_{0}+\alpha_{1} C L C+\alpha_{2} C O C+\alpha_{3} T E C+\alpha_{4} G F C F+\alpha_{5} T L F+U_{t}$

Where $U$ is stochastic or random error term (with usual properties of zero mean and non-serial correlation).

$\alpha_{1-} \alpha_{5}=$ Co-efficient of associated variables

$\alpha_{0}=$ Constant Intercept.

\section{Data Analysis and findings}

1. OLS Regression Results

The Estimated Model for this research study is given below:

$R G D P=212298.316313 * C L C+557.930969453 * C O C-1.94428514011 * T E C+0.114116295241 * G F C F+$

9047.26694476*TLF - 231026.489835

The Table below shows the analysis of the result of the data used in the study. The method of analysis employed is the Ordinary Least Square (OLS).

\begin{tabular}{crrrr}
\hline \hline Variable & Coefficient & Std. Error & t-Statistic & Prob. \\
\hline \hline CLC & 212298.3 & 271299.8 & 0.782523 & 0.4416 \\
COC & 557.9310 & 457.1040 & 1.220578 & 0.2341 \\
TEC & -1.944285 & 4.957867 & -0.392162 & 0.6984 \\
GFCF & $0.114116^{* *}$ & 0.023335 & 4.890409 & 0.0001 \\
TLF & $9047.267 * *$ & 2603.115 & 3.475554 & 0.0020 \\
C & -231026.5 & 98311.09 & -2.349953 & 0.0273
\end{tabular}

$R^{2}=0.949004 ;$ Adj. $R^{2}=0.938379 ;$ F-statistics = 89.32450; Prob(F-statistic $)=0.000000 ;$ DWstat=1.395865; Source: Author's computation

Note: $* * *=$ significant at $1 \% ; * *=$ significant at $5 \%$ and $*=$ significant at $10 \%$

The result of estimation of the model summarized in the table above shows that there is a positive relationship between Real GDP, Coal Consumption, Crude Oil Consumption, Gross Fixed Capital Formation, and Total Labour Force. However, Total Electricity Consumption is negatively related to real gross domestic product. A closer look at the result shows that Gross Fixed Capital Formation and Total Labour Force are statistically significant at 5 percent.

The R-squared which is the coefficient of determination, shows the percentage of variation in the dependent variable that was accounted for by variations in the explanatory variables. It measures the explanatory powers of the model. It is usually between zero and one. A close inspection of the table above indicates that the specified model has a fairly high coefficient of determination. This can be seen from Rsquared of 95 per cent. The R-squared reports that the variables can explain about 95 per cent of total variation in real gross domestic product the remaining 5 per cent variation in the real gross domestic product are not accounted for in the model or rather accounted for by other variables outside the model. The fitness of every 
regression result is based on its $\mathrm{R}$-squared. The adjusted R-squared shows that asymptotically, the variables can explain approximately 94 per cent of total variation. The implication of this is that the model has goodness of fit.

F-statistics test the overall significance of the model under study. F-calculated is compared with Ftabulated where F- cal is greater than F-tab we reject the null hypothesis (Ho) and conclude that the variable is statistically significant in explaining the dependent variable. From the table, it shows that F-statistics is 89.32450; and Prob(F-statistic) is 0.000000 . We, therefore, reject null hypothesis and accept alternative hypothesis. This is because it is greater than the critical values of 2.57 and 3.79 at $1 \%$ and $5 \%$ respectively. Thus, it implies that the model under this study is statistically significantly different from zero. In other words, the explanatory variables jointly considered are significantly important in explaining variation in the dependent variable -real gross domestic product. Durbin - Watson Statistic is given as 1.395865.

\section{Unit Root Test Result}

Literature has established that most time series variables are not stationary. Therefore, using nonstationary variables in the model might lead to spurious regression which cannot be used for precise prediction. (Gujarati, 2003). Hence, our first step is to examine the characteristics of the time series data used for estimation of the model to determine whether the variables have unit roots, that is, whether it is stationary and the order of integration. The Augmented Dickey-Fuller test is used for this purpose. A variable is considered stationary if the absolute ADF value is higher than any of the absolute Mackinnon values. The test is conducted with intercept term.

Table 2: Unit Root Test Summary Statistics (Augmented Dickey Fuller)

\begin{tabular}{|c|c|c|c|c|c|}
\hline \multirow[b]{2}{*}{ Variables } & \multicolumn{2}{|c|}{ ADF Test Statistics } & \multicolumn{2}{|c|}{ Critical Values (5\%) } & \multirow{2}{*}{$\begin{array}{l}\text { Order of } \\
\text { Integration }\end{array}$} \\
\hline & Level & $1^{\text {st }}$ Difference & Level & $1^{\text {st }}$ Difference & \\
\hline CLC & -2.725807 & -4.480645 & -2.967767 & -2.971853 & $\mathrm{I}(1)$ \\
\hline $\mathrm{COC}$ & -2.596839 & -5.718690 & -2.967767 & -2.976263 & $\mathrm{I}(1)$ \\
\hline TEC & -5.185779 & -5.957284 & -2.967767 & -2.976263 & $\mathrm{I}(0)$ \\
\hline GFCF & 2.710669 & -6.454894 & -2.976263 & -2.971853 & $\mathrm{I}(1)$ \\
\hline TLF & -0.618646 & -5.459152 & -2.991878 & -2.991878 & $\mathrm{I}(2)$ \\
\hline RGDP & 4.469724 & -11.82546 & -2.971853 & -3.580623 & $\mathrm{I}(0)$ \\
\hline
\end{tabular}

Source: Author's computation

From the table above the results clearly shows that total electricity consumption and real gross domestic product are stationary at level. Meanwhile, coal consumption, crude oil, total labour force and gross fixed capital formation are non-stationary. This suggests the need to difference the series to obtain stationarity. At first difference, however these variables are integrated of the same order.

\section{Cointegration test results}

Co-integration analysis is carried out to determine the existence of long-run relationship that exist between the dependent variable and its regressor. When one or all of the variables is/are non-stationary at level which means they have stochastic trend. Essentially, it is used to check if the independent variables can predict the dependent variable now (short-run) or in the future (long-run). The long run relationship among the variables were examined using Johasen (1991) conitegration framework. The cointegration result is presented in table 3 below

\section{Granger Causality Test}

In order to examine the Granger causal relationships between the variables under examination we used the estimated model in the previous section. F statistic was used as a testing criterion. The results relating to the existence of Granger causal relationships between the variables are presented in table 3 below.

Table 3: Granger causality tests

\begin{tabular}{|l|l|c|c|}
\hline Dependent Variable & \multicolumn{1}{|c|}{ Testing Hypothesis } & F1 & F2 \\
\hline \multirow{4}{*}{ RGDP } & COC there is a unidirectional relationship(RGDP $\Leftarrow$ COC) & 0.13005 & 3.04571 \\
\cline { 2 - 5 } & CLC- there is no causality (RGDP \#LC) & 1.60186 & 1.29218 \\
\cline { 2 - 5 } & TEC- there is no causality (RGDP $\neq$ TEC) & 0.34041 & 0.17358 \\
\cline { 2 - 5 } & GFCF- there is a unidirectional relationship (RGDP $\Rightarrow$ GFCF) & 5.83016 & 0.91893 \\
\cline { 2 - 5 } & TLF- there is a unidirectional relationship(RGDP $\Rightarrow$ TLF) & 2.59071 & 0.82007 \\
\hline
\end{tabular}




\section{Source: Author's computation}

From table 3 above we can infer that: there is a unidirectional causal relationship between the real gross domestic product and Crude oil consumption with direction from crude oil consumption. Also, there is unidirectional causal relationship between real gross domestic product and gross fixed capital formation and total labour force with direction from real gross domestic product to the two variables. Meanwhile, there is no causal relationship between the real gross domestic product and coal consumption and total electricity consumption.

\section{Conclusion And Policy Implications}

The objective of this study was to examine the direction of causality between economic growth and energy consumption by using an augmented form of Ganger causality test. Our main findings were as follows: First, we found that by testing for stationary of the data used through the unit root process, we realized that all the variables were integrated of the same order. Second, we investigated the direction of causality between the variables using the Granger causality-testing approach, and found out that there is a unidirectional causal relationship between real GDP and crude oil consumption with direction from crude oil consumption. Also, we found that there is a unidirectional causal relationship between gross domestic product and gross fixed capital formation and total labour force with direction from real gross domestic product to the two variables. Meanwhile, there is no causality relationship between coal consumption, total electricity consumption and real GDP.

Based on our findings, the policy implication of this paper is that Nigeria need to invest more in energy sector, particularly in crude oil and natural gas, this is because our results shows that crude oil consumption Granger cause economic growth in the short run. On the demand side, the consumer should be well informed of the importance of the efficient use of electricity consumption, particularly given our finding that total electricity consumption does not contribute to economic growth in the short run

\section{References}

[1] Aqeel, A. and Butt, M. S. (2001). The Relationship between Energy Consumption and Economic Growth in Pakistan. Asia-Pacific Development Journal 8(2): 101-109.

[2] Asafu-Adjaye, J (2000) 'The relationship between energy consumption, energy Prices and economic growth: time series evidence from Asian developing countries'. Energy Economics 22, 615-625

[3] Ayodele, A. S (2004). Improving and sustaining power (electricity) supply for socio economic development in Nigeria.

[4] Birol, F (2007). World energy prospects and challenges. Melbourne: Blackwell publishing.

[5] Central Bank of Nigeria (2000). The Changing Structure of the Nigerian Economy and Implications for development. Lagos: Realms Communications Ltd.

[6] Chontanawat S, Hunt L.C, Pierse R. (2006). Casualty between energy consumption and GDP. From 30 OECD and 78 Non OECD comprises the survey Energy Economics Discussion paper series. ISSN 1749 - 8384.

[7] Community for research and development centre (2006). Renewable energy: The key to sustainable energy development in Nigeria.

[8] Cortright, J. (2001). New growth theory, technology and learning: A practitioner's guide. Portland: Impresa Inc.

[9] Energy information Administration (2007). Country analysis briefs: Nigeria. Retrieved on 12 th November 2007 from www.eia.doe.gov

[10] Energy information Administration (2004). International energy Outlook, Highlights. Retrieved on 12th November 2007 from www.eia.doe.gov

[11] Energy Sector Management Assistance Program (2005). Nigeria: Expanding Access to Rural Infrastructure Issues and Options for Rural Electrification, Water Supply and Telecommunications. Washington, D.C,

[12] ESMAP publications.

[13] Electric Power sector reform Implementation Committee (EPIC) (2004). National electric power policy. Retrieved on 21st July 2007.

[14] Gujarati, D (1995). Basic Econometrics. 3rd Edition. New York: McGraw-Hill, Inc.

[15] Guttormsen, A.G (2004). Causality between Energy consumption and Economic growth. Discussion paper \#D-24/2004. Retrieved on 09th September 2004 from www.nhl.no/ior/

[16] Ikuponisi, F.S (2004, November 21). Status of Renewable Energy in Nigeria. Paper presented at the 2004 conference on Making Renewable Energy a Reality, Abuja. Retrieved July 24, 2007.

[17] Jhingan, M.L (2004). Monetary Economics(6th ed.). Delhi: Vrinda publications Ltd.

[18] Jochem, E (2004). World Energy assessment: Energy and the challenges of sustainability. Energy end - use efficiency, pgs 174217.

[19] Johansson et al (1993). Renewable Energy: Sources for fuel and electricity.

[20] Washington DC, Island press.

[21] Kinika Amaewhule (2000). What are the constraints facing the development and implementation of an energy efficiency policy in Nigeria and how can these be overcome?, (undated). Retrieved on 4th December 2007.

[22] Krizanic, F (2007). The European market of Electricity and Natural Gas. EIBforum, Ljubljana.

[23] Methane to Markets Partnership Coal Subcommittee (2006). Nigeria - Summary of coal in Nigeria. CMM global Overview.

[24] Morimoto, R and Hope, C (2001). The impact of electricity supply on economic growth in Sri Lanka. Judge Institute of Management Research Paper. National Bureau of Statistics (2006).

[25] National Petroleum Council (2003). Balancing Natural Gas Policy: Fuelling the demands of a growing Economy. Washington, D.C: National Petroleum Council.

[26] Nigeria country analysis brief (2005). Retrieved July 24, 2007, from www.parliament.uk/post/home.htm 
[27] Nigerian National Committee of the World Energy Council (NNC-WAC) (2007). Communiqué on Africa forum on energy efficiency. $8-9^{\text {th }}$ January, 2007.

[28] Okpanefe, P.E and Owolabi, S (2001). Small Hydropower in Nigeria. 2001 TCDC Training Workshop on SHP

[29] Oviemuno, A.O (2006). Impact of energy on the manufacturing sector of Nigeria. Retrieved on 01 November 2007 from www.searchwarp.com Prep - Crest (2001). About renewable energy. Retrieved on 28th November 2007 from www.crest.org/efficiency/index.htm

[30] Reddy, M (1998). Energy consumption and Economic activity in Fiji. The Journal of Pacific Studies, Volume 22, 81-96

[31] Roger Bezdek (2007). Renewable Energy and Energy Efficiency: Economic drivers for the 21st century. Colorado: American solar energy society.

[32] Ron, M (2006). Africa's Role in Meeting Energy Demand. London: ISH Inc.

[33] Sanchis, M.T (2007).Quantifying the contribution of electricity to Spanish economic growth during the twentieth Century. Paper presented at the III Iberometrics Valencia, March 23-24, 2007.

[34] Sambo, A. S et al (2006). Nigeria's experience on the application of IAEA's energy models (MAED \& WASP) for national energy planning. Paper presented during the Training Meeting / Workshop on Exchange of Experience in Using IAEA's Energy Models and Assessment of Further Training Needs, held at the Korea Atomic Energy Research Institute, Daejon, Republic of Korea.

[35] Todaro M.P and Smith S.C (2003). Economic Development (eighth edition). Singapore: Pearson Education.

[36] Yu, E. and J. Choi (1985). The causal relationship between energy and GNP, an international comparison. 